\title{
EARLY VERSUS DELAYED ORAL INTAKE IN PATIENTS AFTER CESAREAN SECTION UNDER REGIONAL ANESTHESIA
}

\author{
Laiqa Hassan, Shazia Tufail, Farheen Aslam*, Nilofar Mustafa, Arub Ahmed, Saima Qamar \\ Combined Military Hospital Lahore Medical College, Lahore/National University of Medical Sciences (NUMS) Pakistan, \\ *District Head Quarter Hospital, Vehari Pakistan
}

\begin{abstract}
Objective: To compare the outcome in early versus delayed oral intake in patients after cesarean section under regional anesthesia.

Study Design: Quasi-experimental study.

Place and Duration of Study: Department of Obstetrics and Gynecology, Combined Military Hospital Lahore, from Dec 2017 to May 2018.

Methodology: A total of 352 women undergoing elective cesarean section under regional anesthesia, nil by mouth for at least 8 hours before surgery were divided in 2 groups. In group 1, patients were given sips of clear oral fluid (water) $<5$ hours after cesarean section and in group 2, patients received sips of water 8 hours following surgery. Bowel motility was assessed after surgery on hourly basis. Data about time interval to first bowel movement and ileus were noted.

Results: Mean age of patients was $32.329 \pm 3.44$ years and $33.051 \pm 3.64$ years in group 1 and 2 respectively. Mean gestational age and body mass index was $38.50 \pm 0.93$ weeks and $29.824 \pm 4.97 \mathrm{~kg} / \mathrm{m}^{2}$ in group- 1 versus $37.937 \pm 0.98$ weeks and $27.779 \pm$ $2.81 \mathrm{~kg} / \mathrm{m}^{2}$ in group 2. Mean duration of surgery was $47.096 \pm 6.65$ minutes in group-1 and $47.647 \pm 8.76$ minutes in group 2 . Ileus was seen in $17 \%$ patients in group- 1 and $34.1 \%$ in group-2 $(p<0.001)$. Mean time interval for first bowel movement was $8.323 \pm 1.20$ hours in group-1 and $13.034 \pm 2.54$ hours in group $2(p<0.001)$.

Conclusion: Early feeding after an uncomplicated cesarean section has reduced rate of ileus symptoms and mean time interval for bowel movements to appear.
\end{abstract}

Keywords: Cesarean section, Early oral intake, Gastrointestinal motility, Postoperative complications.

How to Cite This Article: Hassan L, Tufail S, Aslam F, Mustafa N, Ahmed A, Qamar S. Early Versus Delayed Oral Intake in Patients After Cesarean Section Under Regional Anesthesia. Pak Armed Forces Med J 2021; 71(5): 1559-1562. ～doi: https://doi.org/10.51253/pafmj.v71i5.3499

This is an Open Access article distributed under the terms of the Creative Commons Attribution License (https://creativecommons.org/licenses/by-nc/4.0/), which permits unrestricted use, distribution, and reproduction in any medium, provided the original work is properly cited.

\section{INTRODUCTION}

Conventionally, oral intake by the patient is usually withheld after abdominal surgery for a variable period of time, which may be until the evidence of propulsive bowel sounds or the passing of flatus or stool which signifies return of bowel function. ${ }^{1}$ There is a wide variation among the institutional and individual practices which ranges from early oral feeding with fluids to delayed feeding with fluids and food after 24 hours or even more. The discrepancy in practices raises considerable concern about the bases of different practices. During an uncomplicated cesarean section (Csection), the bowels are usually not handled and exposed and so there is minimal disturbance of bowel function. This fact is used an assumption to allow early oral feed after the C-section. ${ }^{2}$

The rate of C-section delivery is increasing around the world. ${ }^{3} \mathrm{C}$-section is an abdominal delivery, and postoperative care in nutrition and hydration is of

Correspondence: Dr Shazia Tufail, Associate Professor of Obstetrics and Gynaecology, CMH Lahore Medical College, Lahore Pakistan Received: 18 Nov 2019; revision received: 06 Feb 2020; accepted: 12 Feb 2020 main concern for women undergoing cesarean delivery. According to Devi et al, a graduated traditional dietary schedule, "nothing by mouth" for 24 hours, or till the return of bowel sounds or the patient passes flatus is still being practiced after C-section. ${ }^{4}$

Recently, there have been recommendations in favor of early oral intake rather than the traditional delayed oral intake after cesarean delivery. 5,6 There have been concerns regarding the effects of early oral intake on postoperative ileus plus other complications after cesarean delivery. ${ }^{7}$ A meta-analysis in 2002 revealed there was no evidence of increased incidence of ileus or other postoperative complications after early oral intake. Rather, there was evidence that gastrointestinal recovery may be improved after early oral intake. ${ }^{8}$

Studies have also shown that there is no increase in gastrointestinal complications if early postoperative oral feeding is started after C-section. ${ }^{9,10}$ Results of international studies cannot be generalized on all populations. Therefore, the objective of our study was to compare the time interval to first bowel movement in early versus delayed oral intake in patients after C-section in 
our general population to get the local evidence on this topic.

The purpose of the study was to compare the management outcomes of early and delayed oral intake in patients after C-section in terms of time interval, which would help us in improving our patient care and reducing the morbidity associated with Csection.

\section{METHODOLOGY}

This quasi-experimental study was conducted in the Obstetrics \& Gynaecology department, Combined Military Hospital Lahore, from December 2017 to May 2018. A minimum sample size of 221 was calculated with $5 \%$ significance level with power of $80 \%$ and $\mathrm{p} 1$ of $10(19.6 \%)$, p2 of $10(31.1 \%)$ where $\mathrm{p} 1$ was the expected proportion (ileus) in population 1 and p2 was the expected proportion (ileus) in population 2. However, a sample size of 352 (176 patients in each group) was finalized for the study. Non-probability consecutive sampling technique was used.

Inclusion Criteria: Women aged 20-40 years, para 1-4 at gestational age 37-40 weeks on ultrasound and nil by mouth for at least 8 hours before surgery undergoing elective $\mathrm{C}$-section under regional anesthesia with operative time between 30-60 minutes were included in the study.

Exclusion Criteria: Women with any associated medical disorder complicating pregnancy like diabetes, hypertension or anemia, intraoperative bowel or omental adhesions or having estimated intraoperative blood loss of more than $1000 \mathrm{ml}$ (blood was measured by using soaked gauzes, pads and blood clots which were weighed and difference of weight of pads and gauzes was calculated before and after use, standardizing one milliliter blood to one gram) were excluded from the study.

Approval of the study was taken from the Research Review Board of the Combined Military Hospital, Lahore (ref. number 54/2017). Demographic information of patients fulfilling the inclusion criteria was taken. Informed consent was taken from each patient while ensuring confidentiality. The subjects were divided into two groups. One hundred and seventy six patients were in early intake group or group 1 while 176 patients were in delayed intake group or group 2 . In group 1, patients were given sips of clear oral fluid (water) at half hourly intervals $<5$ hours after C-section and in group 2, patients received sips of water at half hourly intervals 8 hours following surgery. Bowel motility was assessed after surgery on hourly basis. Data about time interval to first bowel movement and ileus was noted as per operational definition. Data was re-corded on especially designed proforma.

Early oral intake was defined as patients were given sips of clear oral fluid (water) $<5$ hours after Csection. Delayed oral intake: as patients were given sips of oral fluid (water) 8 hours after C-section. An outcome was in terms of mean time interval to first bowel movement and ileus. Mean time interval to first Bowel was the time period from the end of surgery till the detection of first active bowel sounds (by stethoscope) in hours. Bowel motility was assessed after surgery on hourly basis. Ileus was defined as when ultrasound findings show dilated bowel loop (diameter $>2.5 \mathrm{~cm}$ ) and decreased bowel peristalsis after 24 hours of surgery.

All surgeries were done by same surgical team to reduce bias in the study. Data was analyzed with SPSS version-20. Frequency and percentage was computed for qualitative variables, and mean \pm SD was presented for quantitative variables. Chi-square test was applied to compare ileus and the differences in the meantime interval to first bowel movement of the two groups were statistically tested using the student $\mathrm{t}$-test, taking $p \leq 0.05$ as significant.

\section{RESULTS}

A total of 352 patients (176 patients in each group 1 and 2) participated in the study (Table-I), mean age

Table-I: Descriptive statistics of quantitative variables $(n=352)$

\begin{tabular}{l|c|c}
\hline Demographics & $\begin{array}{c}\text { Group 1 } \\
(\mathbf{n = 1 7 6})\end{array}$ & $\begin{array}{c}\text { Group 2 } \\
(\mathbf{n}=176)\end{array}$ \\
\hline Age (years) Mean \pm SD & $32.329 \pm 3.44$ & $33.051 \pm 3.64$ \\
\hline $\begin{array}{l}\text { Gestational age (weeks) } \\
\text { Mean } \pm \text { SD }\end{array}$ & $38.500 \pm 0.93$ & $37.937 \pm 0.98$ \\
\hline $\begin{array}{l}\text { Weight (Kg) } \\
\text { Mean } \pm \text { SD }\end{array}$ & $73.198 \pm 13.66$ & $77.539 \pm 5.34$ \\
\hline $\begin{array}{l}\text { Height (m) } \\
\text { Mean } \pm \text { SD }\end{array}$ & $1.566 \pm 0.09$ & $1.674 \pm 0.06$ \\
\hline $\begin{array}{l}\text { BMI (Kg/m }) \\
\text { Mean } \pm \text { SD }\end{array}$ & $29.824 \pm 4.97$ & $27.779 \pm 2.81$ \\
\hline $\begin{array}{l}\text { Duration of Surgery } \\
\text { (minutes) Mean } \pm \text { SD }\end{array}$ & $47.096 \pm 6.65$ & $47.647 \pm 8.76$ \\
\hline
\end{tabular}

of patients was $32.329 \pm 3.44$ years in group 1 and $33.051 \pm 3.64$ years in group 2 (age range $20-40$ years). Ileus was seen in $30(17 \%)$ patients in group 1 as compare to $146(83 \%)$ in group $2(p<0.001)$ as shown in Table-II. Association of Ileus and time interval for first bowel movement in both groups with regard to age, 
gestational age, parity, BMI and duration of surgery were shown in Table-III.

Table-II: Comparison of ileus and time interval between early and delayed feeding groups $(n=352)$.

\begin{tabular}{|c|c|c|c|c|c|c|}
\hline \multirow{2}{*}{\multicolumn{2}{|c|}{ Groups }} & \multicolumn{5}{|c|}{ Ilues n (\%) } \\
\hline & & \multicolumn{2}{|c|}{ Yes } & \multicolumn{3}{|c|}{ No } \\
\hline \multicolumn{2}{|l|}{ Group 1} & \multicolumn{2}{|c|}{$30(17)$} & \multicolumn{3}{|c|}{$60(34.1)$} \\
\hline \multicolumn{2}{|c|}{ Group 2} & \multicolumn{2}{|c|}{$146(83)$} & \multicolumn{3}{|c|}{$116(65.9)$} \\
\hline \multicolumn{7}{|c|}{$\begin{array}{l}\text { Table-III: Association of early and delayed feeding groups } \\
\text { for age, Parity, BMI and surgery with regard to Ileus. }\end{array}$} \\
\hline \multirow{2}{*}{\multicolumn{2}{|c|}{ Parameters }} & \multicolumn{2}{|c|}{ Group 1} & \multicolumn{2}{|c|}{ Group 2} & \multirow[t]{2}{*}{$\begin{array}{c}p- \\
\text { value }\end{array}$} \\
\hline & & Yes & No & Yes & No & \\
\hline \multirow[t]{2}{*}{$\begin{array}{l}\text { Age } \\
\text { (Years) }\end{array}$} & $\begin{array}{c}20-30 \\
(\mathrm{n}=110)\end{array}$ & $10(9)$ & $\begin{array}{c}16 \\
(14.54)\end{array}$ & $\begin{array}{c}47 \\
(42.7)\end{array}$ & $\begin{array}{c}37 \\
(33.76)\end{array}$ & 0.118 \\
\hline & $\begin{array}{c}31-40 \\
(\mathrm{n}=242)\end{array}$ & $\begin{array}{c}20 \\
(8.27)\end{array}$ & $\begin{array}{c}44 \\
(18.18)\end{array}$ & $\begin{array}{c}99 \\
(40.9)\end{array}$ & $\begin{array}{c}79 \\
(32.65) \\
\end{array}$ & 0.001 \\
\hline \multirow{2}{*}{$\begin{array}{l}\text { Gestational } \\
\text { age } \\
\text { (weeks) }\end{array}$} & $\begin{array}{c}37-38 \\
(n=226)\end{array}$ & $\begin{array}{c}15 \\
(6.64)\end{array}$ & $\begin{array}{c}48 \\
(21.24)\end{array}$ & $\begin{array}{c}72 \\
(31.85)\end{array}$ & $\begin{array}{c}91 \\
(40.27)\end{array}$ & 0.004 \\
\hline & $\begin{array}{c}39-40 \\
(n=126)\end{array}$ & $\begin{array}{c}15 \\
(11.90)\end{array}$ & $\begin{array}{c}12 \\
(9.52)\end{array}$ & $\begin{array}{c}15 \\
(11.90)\end{array}$ & $\begin{array}{c}74 \\
(66.68)\end{array}$ & 0.052 \\
\hline \multirow{2}{*}{ Parity } & $\begin{array}{c}1-2 \\
(n=143)\end{array}$ & $\begin{array}{c}13 \\
(9.09)\end{array}$ & $\begin{array}{c}17 \\
(11.89)\end{array}$ & $\begin{array}{c}76 \\
(53.14)\end{array}$ & $\begin{array}{c}37 \\
(25.88)\end{array}$ & 0.005 \\
\hline & $\begin{array}{c}3-4 \\
(n=209) \\
\end{array}$ & $\begin{array}{c}17 \\
(8.13) \\
\end{array}$ & $\begin{array}{c}43 \\
(20.57) \\
\end{array}$ & $\begin{array}{c}70 \\
(33.49) \\
\end{array}$ & \begin{tabular}{|c}
85 \\
$(37.81)$ \\
\end{tabular} & 0.024 \\
\hline \multirow{2}{*}{$\begin{array}{l}\mathrm{BMI} \\
\left(\mathrm{Kg} / \mathrm{m}^{2}\right)\end{array}$} & $\begin{array}{c}<25 \\
(n=111) \\
\end{array}$ & $\begin{array}{c}1 \\
(0.90) \\
\end{array}$ & $\begin{array}{c}14 \\
(12.61) \\
\end{array}$ & $\begin{array}{c}44 \\
(36.64) \\
\end{array}$ & $\begin{array}{c}52 \\
(49.85) \\
\end{array}$ & 0.004 \\
\hline & $\begin{array}{c}\geq 25 \\
(\mathrm{n}=241)\end{array}$ & $\begin{array}{c}29 \\
(12.03)\end{array}$ & $\begin{array}{c}46 \\
(19.09)\end{array}$ & $\begin{array}{c}102 \\
(42.32)\end{array}$ & $\begin{array}{c}64 \\
(26.56)\end{array}$ & 0.001 \\
\hline \multirow{2}{*}{$\begin{array}{l}\text { Duration } \\
\text { of surgery } \\
\text { (mins) }\end{array}$} & $\begin{array}{c}30-45 \\
(n=116)\end{array}$ & $\begin{array}{c}2 \\
(1.72)\end{array}$ & $\begin{array}{c}13 \\
(11.20)\end{array}$ & $\begin{array}{c}48 \\
(41.37)\end{array}$ & $\begin{array}{c}53 \\
(45.71)\end{array}$ & 0.012 \\
\hline & $\begin{array}{c}46-60 \\
(n=236)\end{array}$ & $\begin{array}{c}27 \\
(11.44)\end{array}$ & $\begin{array}{c}47 \\
(19.92)\end{array}$ & $\begin{array}{c}98 \\
(41.52)\end{array}$ & $\begin{array}{c}63 \\
(27.12)\end{array}$ & 0.001 \\
\hline
\end{tabular}

\section{DISCUSSION}

A steadily growing number of studies suggest early oral feeding after C-section instead of classic view of starting oral fluids or food after the return of bowel movement demonstrated by the passage of flatus. There is sufficient evidence from multiple studies that early initiation of oral feeding is well tolerated and also of considerable benefit to the patients. ${ }^{11-15}$ Most of these studies were conducted in well-equipped specialized hospitals and majority of caesarean sections were performed under general anaesthesia. ${ }^{16}$ In our study, Ileus was seen in $17 \%$ patients in group 1 (early oral intake) as compared to $34.1 \%$ in group $2(p<0.001)$ which was statistically significant. Chantarasorn et al, ${ }^{10}$ in his study also observed that the rate of mild ileus symptoms in the conventional group was significantly higher than the early feeding group $(19.6 \%$ versus $31.1 \%$, $p$-value <0.03). Craciunas et al,17 in his study of 192 women who underwent $\mathrm{C}$-section under both regional and general anaesthesia observed the effect of time of start of oral feeding on patient acceptability and also the benefits on gastrointestinal functions. No significant difference in the incidence of paralytic ileus symptoms was found among the early and conventional feeding groups (15.6\% versus $29.5 \%)$.

Our study was also comparable to a study of 200 women done by Izbizky et al, ${ }^{18}$ who evaluated the effect of early versus delayed feeding on patient satisfaction, and the incidence of ileus considered as a secondary outcome in this study was $17 \%$ versus $16 \%$ among the early and delayed feeding groups. Patolia et $a l, 19$ compared the postoperative outcomes associated with early oral feeding (liquid diet two hours after surgery) versus late oral feeding (liquid diet 8 hours after surgery) in 140 women undergoing elective C-section under regional anaesthesia. There were no significant differences between the two groups in the postoperative gastrointestinal complications. Kovavisarach et $a l,{ }^{20}$ studied that to compared the possible adverse gastrointestinal effects after C-section in 151 women who started intake early compared with those whose first intake was delayed (8 hours versus 24 hours). There were no significant demographic differences between the two groups. It was observed that there had been no significant differences in postoperative gastrointestinal complications between the two groups. Similarly, our study also showed that early oral feeding after C-delivery (8 hours) did not cause any significant adverse gastrointestinal effects compared with delayed oral feeding ( 24 hours). A randomized controlled trial of early initiation of oral feeding after C-section by Jalilian et al, ${ }^{21}$ evaluated the safety and efficacy of early oral feeding after cesarean delivery under general and regional anesthesia in 200 women. In this trial, women in the early feeding group were encouraged to take sips of water 8 hours after the surgery, followed by 100 $\mathrm{ml}$ oral tea at the time of supervision. Women in the routine feeding group received restricted oral intake for the first 24 hours and administration of sips of water 24-48 hours post-operatively. The incidence of symptoms of paralytic ileus was not significantly different between the two groups (15\% versus $13 \%$ ).

Sellers et $a l^{22}$ recommended with-holding of fluids and food for the first 12-24 hours after caesarean section. This was followed by graded oral fluids till full normal fluids were tolerated at about the second postoperative day. Regular diet could be allowed after flatus was passed on about the second postoperative day. Sweet et $a l, 23$ suggested that fluids could be allowed soon after the surgery and a light diet could be started 
when the woman felt ready for intake. Only when the surgeon requests that food be withheld until bowel sounds are heard, should the woman be considered for delayed feeding. In our study, mean time interval for first bowel movement was $8.323 \pm 1.20$ hours in group 1 and $13.034 \pm 2.54$ hours in group $2(p<0.001)$.

Barat and his associates found in a study that for the early oral feeding group, the mean time of the first passage of flatus was found to be $10.2 \pm 1.7$ hours while it was $10.7 \pm 1.6$ hours for the delayed feeding group and the difference was significant. ${ }^{24}$

Devi et al found in another study that women in the early feeding group had significantly shorter time interval to first noticed bowel movement after surgery of $6.97 \pm 0.71$ hours compared with the conventionally fed women with $14.96 \pm 4.97$ hours. ${ }^{4}$

\section{CONCLUSION}

This study has demonstrated early feeding after an uncomplicated cesarean delivery has reduced the rate of ileus symptoms and mean time interval for bowel movements to appear. Further studies with a large sample size are needed to confirm the outcome.

\section{ACKNOWLEDGEMENT}

We thank the anesthetists who participated in the study and the reviewers for their time and constructive feedback.

\section{LIMITATION OF STUDY}

The complexity of interpreting satisfaction which may be related to other aspects of care received in the hospital rather than just the early introduction of oral feeds.

\section{Conflict of Interest: None.}

\section{Authors' Contribution}

LH: Conception, design, analysis, interpretation of data, ST: Conception, design, analysis, interpretation of data, FA: Conception, design, analysis, interpretation of data, NM: Conception, design, analysis, interpretation of data, AA: Conception, design, analysis, interpretation of data, SQ: Conception, design, analysis, interpretation of data.

\section{REFERENCES}

1. Yin X, Ye L, Zhao L, Li L, Song J. Early versus delayed post-operative oral hydration after general anesthesia: a prospective randomized trial. Int J Clin Exp Med 2014; 7(10): 3491-3496.

2. Neu J, Rushing J. Cesarean versus vaginal delivery: long term infant outcomes and the hygiene hypothesis. Clin Perinatol 2011; 38(2): 321331.

3. Kazmi T. Analysis of cesarean section rate-according to robson's 10group classification. Oman Med J 2012; 27(5): 415-417.

4. Devi S, Pillai SK, Vijayaraghavan J. A comparative study of early versus conventional delay in postoperative oral intake in women undergoing cesarean section under regional anaesthesia. Ind J Obstet Gynecol Res 2015; 2(4): 276-282.
5. Dag A, Colak T, Turkmenoglu O, Gundogdu R, Aydin S. A randomized controlled trial evaluating early versus traditional oral feeding after colorectal surgery. Clinics 2011; 66(12): 2001-2005.

6. Adeli M, Razmjoo N, Tara F, Ebrahimzade S. Effect of early post cesarean feeding on gastrointestinal complications. Nurs Mid-wifery Stud 2013; 1(4): 176-181.

7. Bauer AJ, Boeckxstaens GE. Mechanisms of postoperative ileus. Neurogastroenterol Motil 2004; 16(suppl-2): 54-60.

8. Mangesi L, Hofmeyr GJ. Early compared with delayed oral fluids and food after cesarean section. Cochrane Database Sys Rev 2002; 3(1): CD003516.

9. Guo J, Long S, Li H, Luo J, Han D, He T. Early versus delayed oral feeding for patients after cesarean. Int J Gynaecol Obstet 2015; 128(2): 100-105.

10. Chantarasorn V, Tannirandorn Y. A comparative study of early postoperative feeding versus conventional feeding for patients undergoing cesarean section; a randomized controlled trial. J Med Assoc Thai 2006; 89(Suppl-4): S11-16.

11. Masood SN, Masood Y, Naim U, Masood MF. A randomized comparative trial of early initiation of oral maternal feeding versus conventional oral feeding after cesarean delivery. Int J Gynaecol Obstet 2014; 126(2): 115-119.

12. Boban A, Paulus S. The value and impact of anti-Xa activity monitoring for prophylactic dose adjustment of low-molecular-weight heparin during pregnancy: a retrospective study. Blood Coagulation \& Fibrinolysis: Int J Haemost Thromb 2017; 28(3): 199-204.

13. Rolnik DL, Wright D, Poon LC, O'Gorman N, Syngelaki A, de Paco Matallana C, et al. Aspirin versus placebo in pregnancies at high risk for preterm preeclampsia. N Engl J Med 2017; 377(7): 613-622.

14. Barletta JF, Senagore AJ. Reducing the burden of postoperative ileus: evaluating and imple menting an evidence-based strategy. World J Surg 2014; 38(8): 1966-1977.

15. Chapman SJ, Collaborative ES. Ileus Management International (IMAGINE): protocol for a multicentre, observational study of ileus after colorectal surgery. Colorectal Dis 2018; 20(1): 17-25.

16. Gotz M, Braun G, Jakobs R. Fur die Mitglieder der DGVSKommission im Anhang. [German Society of Gastroenterology, Digestive and Metabolic Diseases (DGVS) position statement on endoscopic decompression in acute Ileus]. Z Gastroenterol 2017; 55(12): 1499-1508.

17. Craciunas L, Sajid MS, Ahmed AS. Chewing gum in preventing postoperative ileus in women undergoing caesarean section: a systematic review and meta-analysis of randomised controlled trials. BJOG 2014; 121(7): 793-799.

18. Izbizky GH, Minig L, Sebastiani MA, Otano L. The effect of early versus delayed postcaesarean feeding on women's satisfaction: a randomised controlled trial. BJOG 2008; 115(3): 332-338.

19. Patolia DS, Hilliard RL, Toy EC, Baker B. Early feeding after cesarean: randomized trial. Obstet Gynecol 2001; 98(1): 113-116.

20. Kovavisarach E, Atthakorn M. Early versus delayed oral feeding after cesarean delivery. Int J Gynecol Obstet 2005; 90(1): 31-34.

21. Jalilian N, Fakhri M, Keshavarzi F. A randomised clinical to com-pare the postoperative outcomes of early versus late oral feeding after caesarean section. Life Sci J 2013; 10(8): 212-215.

22. Sellers PM. Midwifery: a textbook and reference book for mid-wives in southern Africa. Kenwyn Juta, 1993, [Internet] Available from: https://www.worldcat.org/title/midwifery-a-textbook-andreference-book-for-midwives-in-southern-africa/oclc/34281991

23. Sweet BR, Tiran D. Mayes' Midwifery. $12^{\text {th }}$ Edition. London: Bail-liere Tindall, 1997, [Internet] Available at: https://www. worldcat.org/title/mayes-midwifery-a-textbook-for-midwives/ oclc/36086459

24. Barat S, Esmaeilzadeh S. Women's satis-faction in early versus delayed postcaesarean feeding: a single-blind randomized controlled trial study. Caspian J Intern Med 2015; 6(2): 67-71. 